Pacific Journal of Mathematic 


\title{
ON LINEAR INDEPENDENCE OF SEQUENCES IN A BANACH SPACE
}

\author{
P. Erdös and E. G. Straus
}

1. A. Dvoretzky has raised the following problem:

Let $x_{1}, x_{2}, \ldots, x_{n}, \ldots$ be an infinite sequence of unit vectors in a Banach space which are linearly independent in the algebraic sense; that is,

$$
\sum_{i=1}^{k} c_{i} x_{n_{i}}=0 \Longrightarrow c_{i}=0 \quad(i=1, \cdots, k)
$$

Does there exist an infinite subsequence $\left\{x_{n_{i}}\right\}$ which is linearly independent in a stronger sense?

We may consider three types of linear independence of a sequence of unit vectors in a normed linear space:

I.

$$
\sum_{n=1}^{\infty} c_{n} x_{n}=0 \Rightarrow c_{n}=0 \quad(n=1,2, \cdots) \text {. }
$$

II. If $\phi(k)>0$ is any function defined for $k=1,2, \ldots$, then

$$
\mid c_{n}^{(k)} i<\phi(k) \quad(n, k=1,2, \ldots)
$$

and

$$
\lim _{k \rightarrow \infty} \sum_{n=1}^{\infty} c_{n}^{(k)} x_{n}=0
$$

imply

$$
\lim _{k \rightarrow \infty} c_{n}^{(k)}=0
$$$$
(n=1,2, \cdots) \text {. }
$$ 
III. $\quad \lim _{k \rightarrow \infty} \sum_{k=1}^{\infty} c_{n}^{(k)} x_{n}=0 \Longrightarrow \lim _{k \rightarrow \infty} c_{n}^{(k)}=0 \quad(n=1,2, \cdots)$.

It is obvious that III implies both II and I; and if

$$
\liminf _{k \rightarrow \infty} \phi(k)>0
$$

then II implies I. It is easy to show that the converse implications do not hold.

In this note we give an affirmative answer to Dvoretzky's question if independence is defined in the sense I or even II for arbitrary $\phi(k)$. However the answer is in the negative if indepence is defined in the sense III.

2. The negative part is proved by the following example due to G. Szegö $[1 ; \mathrm{I}, \mathrm{p} .86]$ :

THEOREM. If $\left\{\lambda_{n}\right\}$ is a sequence of positive number with $\lambda_{n} \rightarrow \infty$, then the functions $\left\{1 /\left(x+\lambda_{n}\right)\right\}$ are complete in every finite positive interval.

Obviously every infinite subsequence of $\left\{1 /\left(x+\lambda_{n}\right)\right\}$ satisfies the condition of the theorem and is therefore complete.

3. For the affirmative part of our result we prove the following:

THEOREM. Let $\left\{x_{n_{i}}\right\}$ be an infinite sequence of algebraically linearly independent unit vectors in a Banach space and let $\phi(k)>0$ be any function defined for $k=1,2, \ldots$. Then there exists an infinite subsequence $\left\{x_{n_{i}}\right\}$ such that $\left|c_{i}^{(m)}\right|<\phi(i)(i, m=1,2, \cdots)$ and

$$
\lim _{m \rightarrow \infty} \sum_{i=1}^{\infty} c_{i}^{(m)} x_{n_{i}}=0
$$

imply

$$
\lim _{n \rightarrow \infty} c_{i}^{(m)}=0
$$$$
(i=1,2, \ldots) \text {. }
$$

It was pointed out to us by the referee that it suffices to prove the theorem for a separable Hilbert space. The separability may be assumed since we may restrict our attention to the subspace spanned by $\left\{x_{n}\right\}$. Now every separable Banach space can be imbedded isometrically in the space $C(0,1)$ of continuous 
functions over the interval $(0,1)$; and $C(0,1) \subset L_{2}(0,1)$, where linear independence, in any of the above defined senses, in $L_{2}$ implies the same independence in $C$. Let $\left\{z_{n}\right\}$ be the orthonormal sequence obtained from $\left\{x_{n}\right\}$ by the Gram-Schmidt process; then

$$
x_{n}=\sum_{m=1}^{n} a_{n m} z_{m},
$$

with $\left|a_{n m}\right| \leq 1$ and $a_{n n} \neq 0$.

Since $\left\{a_{n m}\right\}$ is bounded for fixed $m$, we can select a subsequence $\left\{x_{n_{i}}\right\}$ such that

$$
\lim _{i \rightarrow \infty} a_{n_{i} m}=b_{m}
$$

exists for every $m$.

If we prove the theorem for $\psi(k) \geq \phi(k)$, then it is proved a fortiori for $\phi(k)$. Hence we may set

$$
\psi(n)=\max \{1, \phi(1), \cdots, \phi(n)\}
$$

so that $\psi(n) \geq 1$ and $\psi(n)$ is nondecreasing.

If the theorem we false then for every infinite subsequence $\left\{y_{k}\right\}$ of $\left\{x_{n_{i}}\right\}$ there would exist a sequence of sequences $\left\{c_{k}^{(m)}\right\}$ with

$$
\left|c_{k}^{(m)}\right|<\psi(k) \quad(k, m=1,2, \cdots)
$$

and

$$
\lim _{m \rightarrow \infty} \sum_{k=1}^{\infty} c_{k}^{(m)} y_{k}=Q
$$

while

$$
\limsup _{m \rightarrow \infty}\left|c_{k_{0}}^{(m)}\right| \neq 0 \text { for some fixed } k_{0} \text {. }
$$

We can then select a subsequence of sequences $\left\{c_{k}^{\left(m_{i}\right)}\right\}$ such that

$$
\lim _{i \rightarrow \infty} c_{k}^{\left(m_{i}\right)}=c_{k}
$$


exists for every $k$, and $c_{k_{0}} \neq 0$. For convenience of notation we assume

$$
\lim _{n \rightarrow \infty} c_{k}^{(m)}=c_{k}
$$

Since $c_{k_{0}} \neq 0$, there would exist a least $k_{1} \geq k_{0}$ such that

$$
\left|c_{k}\right|<2^{k-k_{0}} \psi(k)\left|c_{k_{0}}\right|
$$

for all $k>k_{1}$.

This implies

$$
\left|c_{k}^{(m)}\right| \leq 2^{k-k_{1}} \psi(k)\left|c_{k_{1}}^{(m)}\right| \quad \text { for all } k \geq k_{1} ; m>m_{0}
$$

Case $A: b_{n_{i j}}=0$ for $j=1,2, \ldots$.

In order to simplify notation we assume $b_{n_{i}}=0$ for all $i=1,2, \cdots$ by omitting all terms with $n_{i} \neq n_{i_{j}}$ from our subsequence. We select the subsequence $\left\{y_{k}\right\}$ as follows:

$$
y_{1}=x_{n_{1}}, y_{k+1}=x_{n_{k+1}}
$$

where

$$
\left|a_{n_{i_{k+1}}, n_{j}}\right|<\frac{\left|a_{n_{j}, n_{j}}\right|}{4^{k+1} \psi(k+1)}
$$

We write $y_{k}=x_{l_{k}}$.

If the theorem were false then there would exist a sequence of sequences $\left\{c_{k}^{(m)}\right\}$ with the above properties such that

$$
\left\|\sum_{k=1}^{\infty} c_{k}^{(m)} y_{k}\right\|=\epsilon_{m} \rightarrow 0 \text { as } m \longrightarrow \infty \text {. }
$$

If we take the $k_{1}$ defined in $(1)$, then

$$
\left|\sum_{k=k_{1}}^{\infty} c_{k}^{(m)} a_{l_{k}, l_{k_{1}}}\right| \leq \epsilon_{m}
$$

but for all $m>m_{0}$ we have 


$$
\left|c_{k}^{(m)}\right| \leq 2^{k-k_{1}} \psi(k)\left|c_{k_{1}}\right| \quad\left(k=k_{1}, k_{1}+1, \cdots\right),
$$

and hence

$$
\begin{aligned}
\left|\sum_{k=k_{1}+1}^{\infty} c_{k}^{(m)} a_{l_{k}, l_{k_{1}}}\right| & \\
& <\sum_{k=k_{1}+1}^{\infty} \frac{2^{k-k_{1}} \psi(k)\left|c_{k_{1}}\right|\left|a_{k_{k_{1}}, l_{k_{1}}}\right|}{4^{k} \psi(k)}=2^{-2 k_{1}}\left|c_{k_{1}}\right|\left|a_{l_{k_{1}}, l_{k_{1}}}\right|
\end{aligned}
$$

We can now choose $m$ so large that

$$
\left|c_{k_{1}}^{(m)}-c_{k_{1}}\right|<2^{-4 k_{1}}\left|c_{k_{1}}\right|\left|a_{l_{k_{1}}, l_{k_{1}}}\right| \text { and } \epsilon_{m}<2^{-4 k_{1}}\left|c_{k_{1}}\right|\left|a_{l_{k_{1}}, l_{k_{1}}}\right| \text {. }
$$

Then for the left side of (2) we obtain

$$
\begin{aligned}
& \left|\sum_{k=k_{1}}^{\infty} c_{k}^{(m)} a_{l_{k}, l_{k_{1}}}\right| \geq\left|c_{k_{1}}^{(m)}\right|\left|a_{l_{k_{1}}, l_{k_{1}}}\right|-\left|\sum_{k=k_{1}+1}^{\infty} c_{k}^{(m)} a_{l_{k}}, l_{k_{1}}\right| \\
& \quad \geq\left|c_{k_{1}}\right|\left|a_{l_{k_{1}}, l_{k_{1}}}\right|-2^{-4 k_{1}}\left|c_{k_{1}}\right|\left|a_{l_{k_{1}}, l_{k_{1}}}\right|-2^{-2 k_{1}}\left|c_{k_{1}}\right|\left|a_{l_{k_{1}}, l_{k_{1}}}\right| \\
& >2^{-4 k_{1}}\left|c_{k_{1}}\right|\left|a_{l_{k_{1}}, l_{k_{1}}}\right|
\end{aligned}
$$

while for the right side of (2) we have

$$
\epsilon_{m}<2^{-4 k_{1}}\left|c_{k_{1}}\right|\left|a_{l_{k_{1}}, l_{k_{1}}}\right|
$$

a contradiction.

Case B: $b_{n_{i}} \neq 0$ except for a finite number of $i$.

Without loss of generality we may assume $b_{n_{i}} \neq 0$ for all $i$ by omitting a finite number of elements from $\left\{x_{n_{i}}\right\}$. We select the subsequence $\left\{y_{k}\right\}$ as follows:

$$
y_{1}=x_{n_{1}}, y_{k+1}=x_{n_{k+1}}
$$


where

$$
\left|a_{n_{i_{k+1}}}, n_{j}-b_{n_{j}}\right|<\frac{\left|b_{n_{i_{k+1}}}\right|}{4^{k+1} \psi(k+1)} \quad \text { for } j=1,2, \cdots, i_{k} \text {. }
$$

For simplicity we again write $y_{k}=x_{l_{k}}$ 。

If the theorem were false then there would exist sequences $\left\{c_{k}^{(m)}\right\}$ with the foregoing properties such that

$$
\left\|\sum c_{k}^{(m)} y_{k}\right\|=\epsilon_{m} \longrightarrow 0 \quad \text { as } m \rightarrow \infty
$$

If we let $k_{1}$ be defined as in (1), then on the one hand we have

$$
\begin{aligned}
Q & =\left|\frac{1}{b_{l_{k_{1}}}} \sum_{k=k_{1}}^{\infty} c_{k}^{(m)} a_{l_{k}, l_{k_{1}}}-\frac{1}{b_{l_{k_{1}+1}}} \sum_{k=k_{1}+1}^{\infty} c_{k}^{(m)} a_{l_{k}, l_{k_{1}+1}}\right| \\
& \geq\left|c_{k_{1}}^{(m)}\right|-\frac{\left|c_{k_{1}}^{(m)}\right|}{4^{k_{1}}}-\sum_{k=k_{1}+1}^{\infty} \frac{2\left|c_{k}^{(m)}\right|}{4^{k} \psi(k)} \\
& \geq\left|c_{k_{1}}^{(m)}\right|\left(1-\frac{1}{4^{k_{1}}}-\sum_{k=k_{1}+1}^{\infty} \frac{2 \cdot 2^{k-k_{1}} \psi(k)}{4^{k} \psi(k)}\right)>\frac{1}{2}\left|c_{k_{1}}^{(m)}\right|>\frac{1}{4}\left|c_{k_{1}}\right|>0
\end{aligned}
$$

for all $m>m_{0}$; on the other hand, we have

$$
\begin{aligned}
Q & \leq \frac{1}{b_{l_{k_{1}}}}\left\|\sum_{k=1}^{\infty} c_{k}^{(m)} y_{k}\right\|+\frac{1}{b_{l_{k_{1}}+1}}\left\|\sum_{k=1}^{\infty} c_{k}^{(m)} y_{k}\right\| \\
& \leq\left(\frac{1}{b_{l_{k_{1}}}}+\frac{1}{b_{l_{k_{2}}}}\right) \in_{m}<\frac{1}{4}\left|c_{k_{1}}\right|
\end{aligned}
$$

for all sufficiently large $m$, a contradiction.

\section{REFERENCES}

1. R. Courant, D. Hilbert, Mothoden der mathematischen Physik, Berlin, 1931. 


\title{
PACIFIC JOURNAL OF MATHEMATICS
}

\author{
EDITORS
}

\author{
R. M. BOEINSON \\ University of California \\ Berkeley 4, California \\ E. HEWITT \\ University of Washington \\ Seattle 5, Washington
}

\author{
P. P. DILWOR TH \\ California Institute of Technology \\ Pasadena 4, California \\ E. F. BECKENBACH \\ University of California \\ Los Angeles 24, California
}

\section{ASSOCIATE EDITORSS}

$\begin{array}{llll}\text { H. BUSEMANN } & \text { P. R. HALMOS } & \text { BØRGE JESSEN } & \text { J. J. STOKER } \\ \text { HERBERT FFDERER } & \text { HEINZ HOPF } & \text { PAUL LÉVY } & \text { E. G. STR AUS } \\ \text { MARSHALL HALI } & \text { R. D. JAMES } & \text { GEORGE PÓLYA } & \text { KÔSAKU YOSIDA }\end{array}$

\section{SFONSORS}

UNIVERSITY OF BRITISH COLUMBIA

CALIFORNIA INSTITUTE OF TECHNOLOGY.

UNIVERSITY OF CAIIFORNIA, BERKELEY

UNIVERSITY OF CALIFORNIA, DAVIS

UNIVERSITY OF CALIFORNIA, LOS ANGELES

UNIVERSITY OF CALIFORNIA, SANTA BARBARA

UNIVERSITY OF NEVADA

OREGON STATE COLLEGE

UNIVERSITY OF OREGON

\author{
UNIVERSITY OF SOU THERN CALIFORNIA \\ STANFORD RESEARCH INSTITUTE \\ STANFORD UNIVERSITY. \\ WASHINGTON STATE COLLEGE \\ UNIVERSITY OF WASHINGTON \\ AMERICAN MATHEMATICAL SOCIETY \\ NATIONAL BUREAU OF STANDARDS, \\ INSTITUTE FOR NUMERICAL ANALYSIS
}

Mathematical papers intended for publication in the Pacific Journal of Mathematics should be typewritten (double spaced), and the author should keep a complete copy. Manuscripts may be sent to any of the editors-except Robinson, whose term expires with the completion of the present volume; they might also be sent to M.M. Schiffer, Stanford University, Stanford, California, who is succeeding Robinson. All other communications to the editors should be addressed to the managing editor, $\mathrm{E}$. F. Beckenbach, at the address given above.

Authors are entitled to receive 100 free reprints of their published papers and may obtain additional copies at cost.

The Pacific Journal of Mathematics is published quarterly, in March, June, September, and December. The price per volume (4 numbers) is $\$ 8.00$; single issues, $\$ 2.50$. Special price to individual faculty members of supporting institutions and to individual members of the American Mathematical Society: $\$ 4.00$ per volume; single issues, $\$ 1.25$.

Subscriptions, orders for back numbers, and changes of address should be sent to the publishers, University of California Press, Berkeley 4, California.

Printed at Ann Arbor, Michigan. Entered as second class matter at the Post Office, Berkeley, California.

\author{
UNIVERSITY OF CALIFORNIA PRESS - BERKELEY AND LOS ANGELES
}




\section{Pacific Journal of Mathematics}

\section{Vol. 3, No. $4 \quad$ June, 1953}

Paul Erdős and Gilbert Agnew Hunt, Jr., Changes of sign of sums of random variables........................................ 673

Paul Erdôs and Ernst Gabor Straus, On linear independence of sequences in

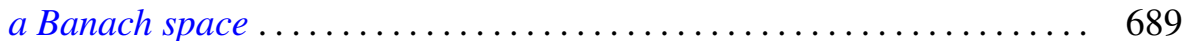

Haim Hanani, On sums of series of complex numbers ............... 695

Melvin Henriksen, On the prime ideals of the ring of entire functions ..... 711

Irving Kaplansky, Completely continuous normal operators with property L............................................. 721

Samuel Karlin, Some random walks arising in learning models. I. ...... 725

William Judson LeVeque, On uniform distribution modulo a subdivision ..................................... 757

Lee Lorch, Derivatives of infinte order ..................... 773

Ernest A. Michael, Some extension theorems for continuous functions . . . . . 789

Tyre Alexander Newton, A note on the Hölder mean ................ 807

Raymond Moos Redheffer, On a theorem of Plancherel and Pólya....... 823

Choy-Tak Taam, On the complex zeros of functions of Sturm-Liouville

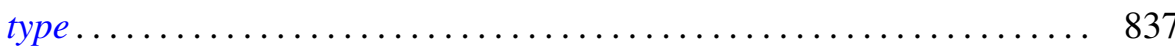

